\title{
Complete and Partial Deficiencies of Complement Factor D in a Dutch Family
}

\author{
Pieter S. Hiemstra, ${ }^{\ddagger}$ Ema Langeler, ${ }^{\star}$ Betty Compier, ${ }^{5}$ Yvonne Keepers, ${ }^{\star}$ Peter C. J. Leijh, ${ }^{\ddagger}$ \\ Maria Th. van den Barselaar," David Overbosch, ${ }^{\mathbf{5}}$ and Mohamed R. Daha* \\ ${ }^{*}$ Departments of Nephrology and ${ }^{\ddagger}$ Infectious Diseases, University Hospital, Leiden; and ${ }^{\S}$ Red Cross Hospital, The Hague, The Netherlands
}

\begin{abstract}
A young man suffering from recurrent Neisseria infections was shown to lack detectable serum complement factor $D$ hemolytic activity. Addition to the patient's serum of purified factor $D$ to a final concentration of $1 \mu \mathrm{g} / \mathrm{ml}$ resulted in full restoration of the activity of the alternative pathway. Using an enzymelinked immunosorbent assay, it was shown that the patient's serum did not contain measurable amounts of factor $D$ antigen either. The sister, the father, as well as the parents of the mother had factor $D$ levels within the normal range, and the factor $D$ level of the mother was decreased. The capacity of the patient's serum, at concentrations up to $5 \%$, to promote phagocytosis of Escherichia coli by normal human granulocytes was low when compared to normal serum. Substitution of the patient's serum with purified factor $D$ resulted in a full restoration of opsonic activity. This study describes the first complete deficiency of factor $\mathrm{D}$, and demonstrates its possible relation to recurrent Neisseria infections.
\end{abstract}

\section{Introduction}

The role of the complement system in the defence against infectious agents and in the clearance of immune complexes has been studied in detail both in vitro and in vivo. The prevalence of complement deficiencies in patients with bacterial infections and a variety of autoimmune disorders is well documented. For instance it has been shown that the incidence of heterozygous $\mathrm{C} 2$ deficiencies in the general population is low $(1.2 \%)$, but a higher incidence $(5.9 \%)$ has been reported in patients with systemic lupus erythematosus (1). In patients suffering from disseminated Neisserial infections the incidence of deficiencies in the terminal components of the complement system may be as high as $10-15 \%$ (2).

The complement system is composed of 14 plasma proteins, and its activity is regulated by five fluid-phase and four membrane-bound regulatory proteins. Complement deficiencies have been described for all components of the classical and terminal pathways, and for the components of the alternative pathway except for factor B (reviewed in reference 3 ). The (functional) deficiency of the regulatory proteins C1-Inactiva-

Presented in part at the XIIth International Complement Workshop, Chamonix, France and published in abstract form in 1987. (Complement. 4: 167.)

Address reprint requests to Dr. Hiemstra, Department of Infectious Diseases, Building 1, C5-P, University Hospital Leiden, P. O. Box 9600, 2300 RC Leiden, The Netherlands.

Received for publication 5 December 1988 and in revised form 2 August 1989

J. Clin. Invest.

(C) The American Society for Clinical Investigation, Inc.

0021-9738/89/12/1957/05 \$2.00

Volume 84, December 1989, 1957-1961 tor (C1-In) ${ }^{1}$ and decay-accelerating factor (DAF) is associated with hereditary angioneurotic edema and paroxysmal nocturnal hemoglobinuria, respectively. Defects in the inhibitors factor I (4-8) and factor H (partial) (9), properdin (P) (10), and a partial functional deficiency of factor $D(11)$ have been described. Except for the partial factor $\mathrm{H}$ deficiency, all these deficiencies were accompanied by recurrent infections.

In the present study a patient, suffering from recurrent Neisseria infections, with a defect in the activity of the alternative pathway is described. No hemolytic activity of factor D could be demonstrated in the patient's serum. The availability of an antiserum against factor $D$ enabled us to demonstrate the complete absence of factor $\mathrm{D}$ antigen in the serum of the patient, and low levels in the serum of his mother.

\section{Methods}

\section{Case history}

In 1985, a 24-yr-old male was admitted to the Red Cross Hospital (The Hague, The Netherlands) because of fever, arthralgias, myalgia, and a generalized rash. The patient had recurrent episodes of high temperature with intervals of well-being. Extensive laboratory analysis of blood and urine showed no abnormalities. The $\mathrm{CH}_{50}$ test, a hemolytic activity assay for the whole complement system, however, was decreased, and activity in the $\mathrm{AP}_{50}$ test, a measure for the alternative and terminal pathways, was shown to be absent. The patient's IgG, IgM, and IgA concentrations were normal. Subclass analysis of IgG (kindly performed by Dr. P. Bird, Newcastle upon Tyne, UK) showed no abnormalities. Blood cultures were repeatedly negative, until the blood sample taken on day 32, which was shown to contain Neisseria gonorrhoeae. The patient has been treated with penicillin $\mathrm{G}$, which was changed to cefotaxime after $20 \mathrm{~d}$ because of a penicillin allergy. Since the patient recovered, he has been well.

In 1975 (when the patient was 14 yr old) he was admitted to a hospital because of meningococcal meningitis. The patient was then successfully treated with penicillin $G$ and sulfonamides. At the age of 19, the patient was again admitted to the Red Cross Hospital, and blood cultures revealed the presence of $N$. gonorrhoeae.

\section{Materials}

Factor D. Factor D was purified from $3,000 \mathrm{ml}$ normal human plasma essentially according to published procedures (12). Final purification was performed by ion exchange chromatography (TSK CM-3SW; LKB Produkter AB, Bromma, Sweden) in a high performance liquid chromatography set up (LKB Produkter AB). Upon analysis using 13\% SDS-PAGE (13) only one band corresponding to a molecular weight of $24 \mathrm{kD}$ was detected.

Antiserum against factor $D$. To obtain antibodies against factor $\mathrm{D}$, a rabbit was immunized with a conjugate of bovine thyroglobulin (BTG) (14) and factor D in complete Freund adjuvant. To prepare the

1. Abbreviations used in this paper: $\mathrm{AP}_{50}$, hemolytic activity assay for the alternative and terminal pathway; BTG, bovine thyroglobulin; $\mathrm{CH}_{50}$, hemolytic activity assay for the whole complement system; C1-In, C1-Inactivator; DAF, decay-accelerating factor; HRP, horseradish peroxidase; NBCS, newborn calf serum; $P$, properdin. 
factor D-BTG conjugate, $110 \mu \mathrm{g}$ factor D was mixed with $500 \mu \mathrm{g}$ BTG in a final volume of $3 \mathrm{ml}$ PBS containing $0.05 \%$ glutaraldehyde. After incubation for $1 \mathrm{~h}$ at room temperature, the mixture was dialyzed against PBS containing $2 \mathrm{mM}$ EDTA for $16 \mathrm{~h}$ at $4^{\circ} \mathrm{C} .500 \mu \mathrm{l}$ factor D-BTG was mixed with an equal amount of complete Freund adjuvant for each of the three immunizations. A 33\% ammonium sulfate precipitate of the antiserum was affinity purified using an immunosorbent of partially purified factor $\mathrm{D}$.

ELISA for factor D. Microwells (Titertek, Flow Laboratories, Zwanenburg, The Netherlands), were coated by overnight incubation at room temperature with $100 \mu \mathrm{l}$ anti-D at $6 \mu \mathrm{g} / \mathrm{ml}$ in carbonate buffer at pH 9.6 (all reaction volumes were $100 \mu \mathrm{l}$ ). After washing, the plates were incubated with a sample containing factor D diluted in PBS containing $0.05 \%$ Tween- 20 and $1 \%$ heat-inactivated $\left(30 \mathrm{~min}\right.$ at $\left.56^{\circ} \mathrm{C}\right)$ newborn calf serum (PBS-Tw-NBCS) for $1 \mathrm{~h}$ at room temperature. Next the plates were washed, and anti-D conjugated to biotin (Zymed Laboratories Inc., San Francisco, CA) was added, and incubated for 1 $h$ at $37^{\circ} \mathrm{C}$. Binding of anti-D biotin was detected using streptavidin conjugated to horseradish peroxidase (HRP) (Zymed Laboratories Inc.), and subsequent incubation with $O$-phenylenediamine (Sigma Chemical Co., St. Louis, MO) as a substrate for the HRP. The reaction was stopped by the addition of $25 \mu \mathrm{l} 1 \mathrm{M} \mathrm{H}_{2} \mathrm{SO}_{4}$, and the OD was read at $\mathrm{OD} 492 \mathrm{~nm}$. The assay was calibrated using purified factor $D$.

Complement assays. Hemolytic titrations for $\mathrm{CH}_{50}(15), \mathrm{AP}_{50}, \mathrm{Cl}$, C4, C3 (16), factor D (17) were performed as described. C1q, C4, C3, factor $\mathrm{B}$, factor $\mathrm{H}$, factor $\mathrm{I}$, and $\mathrm{CI}-\mathrm{In}$ were determined by radial immunodiffusion using monospecific antisera as described (18). Immunochemical quantitation of $C 2$ and $\mathrm{P}(19)$ was kindly performed by Dr. A. Sjöholm (Department of Immunology, Institute of Medical Microbiology, Lund, Sweden).

Fractionation of patient's serum. Patient's or normal serum was fractionated by gel filtration on a $1.5 \times 90 \mathrm{~cm}$ column of Sephadex G-75. The column, equilibrated in Veronal-buffered saline containing $0.15 \mathrm{M} \mathrm{NaCl}$ and $2 \mathrm{mM}$ EDTA, was run in the same buffer at a flow rate of $4.5 \mathrm{ml} / \mathrm{h}$. Fractions $(1.5 \mathrm{ml})$ were collected and assayed for protein content by the Folin method, and for factor D using the hemolytic assay and the ELISA. In addition, "trypsin-activatable" factor D activity was assessed as described (11).

Phagocytosis assay. The capacity of the patient's serum to promote the phagocytosis of $E$. coli by normal human granulocytes was determined essentially as described (20). Briefly, $5 \times 10^{6}$ granulocytes were mixed with $5 \times 10^{6}$ serum resistant $E$. coli 054 in the presence of various concentrations of serum in a final volume of $1,100 \mu \mathrm{l}$ HBSS containing $0.1 \%$ gelatin (HBSS-gelatin). After different periods of incubation at $37^{\circ} \mathrm{C}$ and under slow rotation at $4 \mathrm{rpm}, 250-\mu 1$ samples were withdrawn and added to $750 \mu 1$ ice-cold HBSS-gelatin. Next granulocytes and granulocyte-associated bacteria were pelleted by centrifugation for $4 \mathrm{~min}$ at $110 \mathrm{~g}$, and the number of viable bacteria in the supernatant was determined by a microbiological assay. The percentage phagocytosis was determined as the decrease in the number of viable nongranulocyte associated bacteria, and corrected for the growth of bacteria in the absence of granulocytes (20).

\section{Results}

Extensive immunological investigation of the patient only revealed a decreased $\mathrm{CH}_{50}$ and the absence of $\mathrm{AP}_{50}$ activity. To gain insight into the cause of these abnormalities, an analysis of the individual complement components was performed (Table I). In addition to the abnormalities in the $\mathrm{CH}_{50}$ and $\mathrm{AP}_{50}$, a complete functional deficiency of factor $\mathrm{D}$ was observed. All the other components of the alternative and classical pathway were normal.

Because factor D activity in the patient's serum was investigated in a functional assay using D-depleted serum, the lack of factor $D$ activity in the patient's serum could be caused by a
Table I. Assay of Complement Components in Patient's Serum

\begin{tabular}{lcc}
\hline \multicolumn{1}{c}{ Test } & Patient's serum & Normal $^{*}$ \\
\hline CH50 & $\underline{173}$ & $256-580$ \\
AP50 & $\leq 1$ & $8-24$ \\
C1q* & 130 & $100-140$ \\
C1 $^{\ddagger}$ & $115 \%$ & 100 \\
C4 $^{\ddagger}$ & $99 \%$ & 100 \\
C4 $^{*}$ & 270 & $170-300$ \\
C2 $^{\S}$ & 95 & $77-159$ \\
C3 $^{\ddagger}$ & $132 \%$ & 100 \\
C3 $^{*}$ & 1140 & $680-1040$ \\
C3-9 $^{*}$ & 16 & $13-22$ \\
B $^{*}$ & 190 & $130-220$ \\
D & 0 & $25-105$ \\
P $^{\$}$ & 140 & $54-157$ \\
Factor H* & 210 & $190-260$ \\
Factor I* & 720 & $560-740$ \\
C1-In & 350 & $290-410$ \\
& & \\
\hline
\end{tabular}

Expressed in $\mathrm{U} / \mathrm{ml},{ }^{*} \mu \mathrm{g} / \mathrm{ml},{ }^{\ddagger} \%$ of normal or ${ }^{\S} \%$ of pooled reference serum (20).

Values below the normal range (deduced from the mean concentration \pm 2 SD of 40 healthy blood donors) are underlined.

functional deficiency of factor D. To characterize the nature of the deficiency, an ELISA specific for factor D was developed. Using this ELISA, a dose-dependent reaction was observed using normal human serum, whereas the patient's serum did not react (Fig. 1). This absence of factor D function and antigen could be due to inhibition of factor $\mathrm{D}$ activity by binding to other serum components. To exclude this possibility, normal and patient's serum was fractionated on a Sephadex G-75 column and the fractions were assessed for factor D (Fig. 2). Factor D functional and antigenic activity was observed in the same fractions upon gel filtration of normal human serum, but no activity was detected in the fractions of patient's serum. These data also demonstrate the specificity of the factor D ELISA. In addition, each fraction was treated with $10 \mu \mathrm{g} / \mathrm{ml}$ of trypsin. This did not result in the detection of factor D, suggesting an absence of "trypsin-activatable" factor D.

Next the capacity of purified factor $\mathrm{D}$ to restore the $\mathrm{AP}_{50}$ activity of the patient's serum was investigated. Addition of 1 $\mu \mathrm{g} / \mathrm{ml}$ of factor D to the patient's serum resulted in full restoration of $\mathrm{AP}_{50}$ activity to the same level as that observed in normal human serum (Fig. 3 ). These results exclude a possible inhibition of factor D activity in the patient's serum.

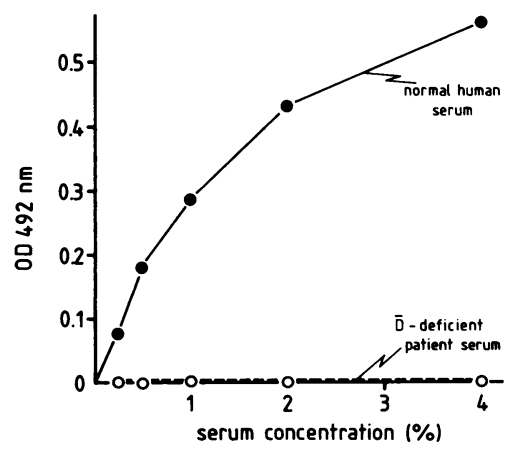

Figure 1. Detection of factor $D$ in serum. Normal human serum (•) and patient's serum (O) were tested in various concentrations in an ELISA specific for factor D. 


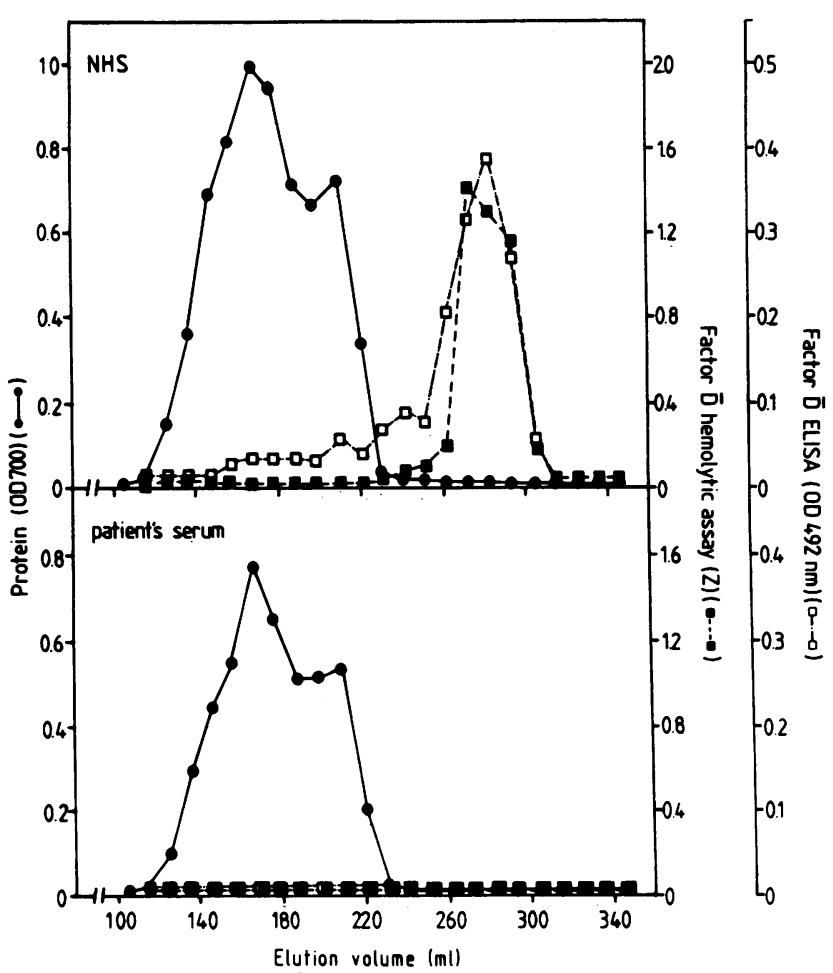

Figure 2. Gel filtration of NHS or patient's serum on Sephadex G-75. $1 \mathrm{ml}$ of NHS or patient's serum was fractionated on a Sephadex G-75 column, and the fractions were assessed for protein (•), factor D hemolytic activity ( $\square$ ), and factor D antigen ( $\square$ ).

Since the alternative pathway is involved in the opsonization of microorganisms that activate the alternative pathway, the opsonic activity of the patient's serum was investigated. Granulocytes, obtained from a healthy volunteer, were incubated with different concentrations of patient serum in the presence or absence of purified factor $\mathrm{D}$, and a constant number of $E$. coli 054 . In the presence of normal AB serum, a concentration- and time-dependent phagocytosis was observed (Fig. 4). Little phagocytosis occurred in the presence of 1,5 , or $10 \%$ patient serum. Reconstitution of the patient serum with purified factor $\mathrm{D}$ to a final concentration of 5 $\mu \mathrm{g} / \mathrm{ml}$ resulted in increase in the extent of phagocytosis to the same level as that observed in the presence of normal $A B$ serum.

To gain insight into the mode of inheritance of the factor $D$ deficiency, a limited family study was performed. All family

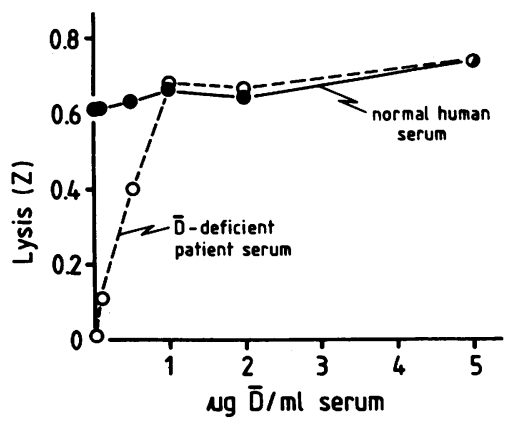

Figure 3. Effect of substitution with factor $D$ on $\mathrm{AP}_{50}$ activity. 1 $\times 10^{7}$ rabbit erythrocytes were incubated in $1.25 \%$ NHS or patient's serum containing various concentrations of purified factor $\mathrm{D}$ in a final volume of $200 \mu \mathrm{l}$ MgEGTA-DGVB $^{2+}$ for $60 \mathrm{~min}$ at $37^{\circ} \mathrm{C}$, and the extent of lysis $(Z)$ was assessed.

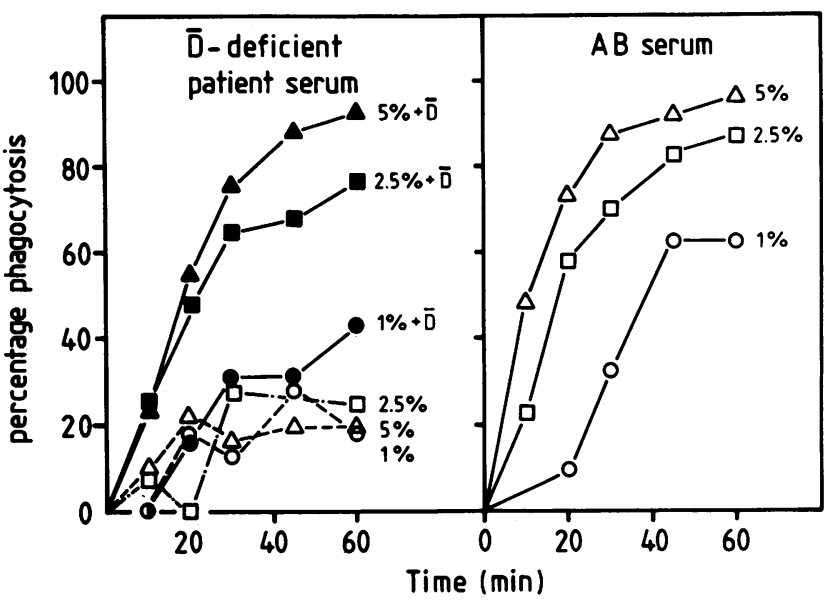

Figure 4. Effect of substitution of serum with factor D on the phagocytosis of $E$. coli by human granulocytes. $5 \times 10^{6}$ granulocytes were incubated for indicated periods at $37^{\circ} \mathrm{C}$ and under slow rotation at 4 $\mathrm{rpm}$ with $5 \times 10^{6} \mathrm{E}$. coli 054 in the presence of various concentrations of patient's serum, in the presence or absence of purified factor $\mathrm{D}$, or normal AB serum. After centrifugation of the granulocytes and granulocyte-associated bacteria, the number of viable bacteria in the supernatant was determined, and used to calculate the percentage phagocytosis.

members studied were clinically healthy and did not have a medical history of recurrent infections. The hemolytic activities of the total complement system $\left(\mathrm{CH}_{50}\right)$ were decreased in the serum of the patient, his mother and his sister (Table II). The activity of the alternative pathway $\left(\mathrm{AP}_{50}\right)$ and factor $\mathrm{D}$ were absent in the patient serum and decreased in the serum of the mother and in one of the two serum samples of the sister. In addition, phagocytosis of $E$. coli in the presence of $1 \%$ serum of the mother and sister was decreased, whereas phagocytosis in 2.5 or $5 \%$ serum was normal (results not shown). No abnormalities were observed in the serum of the father and the parents of the mother. Using these data, a family tree was constructed (Fig. 5).

Table II. Assay of Complement Components in the Serum of the Patient and His Relatives

\begin{tabular}{lcccc}
\hline & \multicolumn{4}{c}{ Test } \\
\cline { 2 - 5 } & CH50 & AP50 & D & $D^{*}$ \\
\hline Patient & $\underline{173 / 128^{\ddagger}}$ & $\underline{\leq 1 /<1}$ & $\underline{0 / 0}$ & $\underline{0 / 0}$ \\
Father & $472 / 475$ & $14 / 9.4$ & $28 / 52.3$ & $0.85 / 1.65$ \\
Mother & $\underline{177 / 185}$ & $\underline{4 / 2.9}$ & $\underline{14 / 20.6}$ & $\underline{0.53 / 0.53}$ \\
Sister & $\underline{255 / 233}$ & $\underline{4 / 1.6}$ & $\underline{17 / 29.1}$ & $0.77 / 0.94$ \\
Grandmother & 367 & 16.3 & 95.0 & 1.28 \\
Grandfather & 311 & 22.2 & 37.8 & 1.09 \\
Normal & $256-580$ & $8-24$ & $25-105$ & $0.66-1.22$ \\
\hline
\end{tabular}

Expressed in $\mathrm{U} / \mathrm{ml}$ or ${ }^{*} \mu \mathrm{g} / \mathrm{ml}$

₹ Sera obtained on two occasions with an interval of one year.

Values below the normal range are underlined. The normal range was defined as described in the legend to Table I, except for factor D antigen, which was deduced from the mean \pm 2 SD of 20 healthy blood bank donors. 


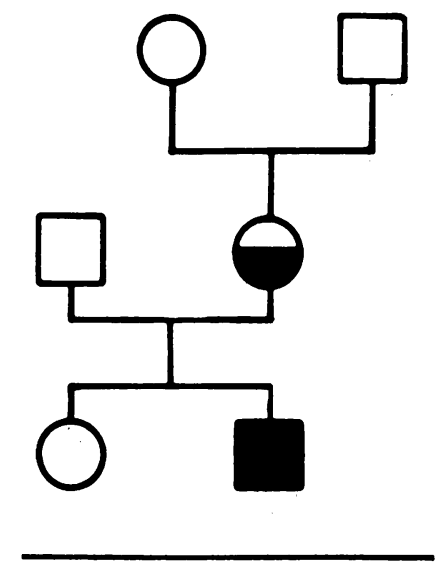

Figure 5. Family tree of the patient with factor D deficiency. The patient with the complete deficiency is represented by a closed square, and the mother with a partial deficiency by a half-closed circle.

\section{Discussion}

A young man suffering from recurrent Neisseria infections was found to have a complete deficiency of factor D of the alternative pathway. Factor $\mathrm{D}$ is a serine protease with a molecular weight of 24,000 , which is involved in the formation of the $\mathrm{C} 3$ convertase of the alternative pathway. It cleaves factor B present in a $\mathrm{Mg}^{2+}$-dependent complex with $\mathrm{C} 3 \mathrm{~b}(21,22)$. Its amino acid sequence $(12,23)$ and partial DNA sequence $(24)$ have been described. It is present in a presumably active form in serum, and no inhibitors present in serum have been described (22). The serum concentration is $1-2 \mu \mathrm{g} / \mathrm{ml}(12,22$, $25,26)$. Factor $D$ is probably filtered through the glomerulus and, under normal conditions, nearly completely reabsorbed within the tubules (27).

The patient described in this study is the first case of a complete factor D deficiency. A previous report (11) described a twin with a partial (8\% of normal levels) deficiency of factor D. Apparently the defect in the present case is inherited, since the mother shows half-normal levels of factor $D$. The factor $D$ levels in the father, the sister and parents of the mother of the patient were within the normal range. This can be explained by an X-linked mode of inheritance, as has been described for properdin deficiency $(10,28)$, in which the putative new mutation has occurred in the mother. Further studies are clearly required to support this suggestion. In addition, further studies are required to explain the wide variety in specific activities of factor $D$ in the sera studied in Table II. The deficiency of factor $D$ was demonstrated by the lack of factor $D$ functional activity (Table I), and by the absence of factor D antigen (Fig. 1). Reconstitution of the serum with purified factor D could restore the defective functions in $\mathrm{AP}_{50}$ (Fig. 3) and opsonic (Fig. 4) activity and C3 cleavage induced by incubation with zymosan (unpublished observation). In addition to the defect in factor $\mathrm{D}$, decreased $\mathrm{CH}_{50}$ activity was observed in the patient, his mother, and sister. Since in these serum samples, C2 functional activity, in contrast to $\mathrm{C} 2$ antigen, was also decreased (results not shown), this may be explained by an increased consumption of $\mathrm{C} 2$ in vitro after taking the blood sample.

In contrast to the previously described partial deficiency of factor $\mathrm{D}$, the total deficiency described in this paper is associated with $N$. meningitidis and $N$. gonorrhoea infections. These infections have also been related to deficiencies of the components of the terminal pathway (2), and infections with $N$. meningitidis can be associated with properdin deficiencies (28). The patient has now been vaccinated against meningococcal infections, and because the patient has an intact classical and terminal pathway of complement, this is expected to prove helpful. The results of the present study support the recommendation that an analysis of the complement components is required in patients with recurrent neisserial infections (29). This analysis should not only consist of a standard $\mathrm{CH}_{50}$ test, but should also include an assay for the activity of the alternative pathway $\left(\mathrm{AP}_{50}\right)$.

\section{Acknowledgments}

The authors thank Professor L. A. van Es, Professor R. van Furth, and Dr. J. D. Macfarlane for helpful discussions and critically reading the manuscript, Mrs. A. van Seggelen and M. E. Stuurman for expert technical assistance, and Mrs. C. J. M. van der Voort and Ms. M. L. Kluiters for secretarial assistance.

This study was supported in part by the Foundation for Medical Research (MEDIGON), which is subsidized by The Netherlands Organization for Scientific Research (NWO).

Note added in proof. It has recently been reported that mouse adipsin has factor D activity, and that in experimental models of obesity in animals functional activities of factor $\mathrm{D}$ are decreased (Rosen et al. 1989. Science [Wash. DC]. 244:1483-1487). Therefore, it is of interest to note that the patient described in this paper did not suffer from obesity.

\section{References}

1. Glass, D., D. Raum, D. Gibson, J. S. Stillman, and P. H. Schur. 1976. Inherited deficiency of the second component of complement. Rheumatic disease associations. J. Clin. Invest. 58:853-861.

2. Ross, S. C., and P. Densen. 1984. Complement deficiency states and infection: epidemiology, pathogenesis and consequences of Neisserial and other infections in an immune deficiency. Medicine (Baltimore). 63:243-273.

3. Fries, L. F., J. J. O'Shea, and M. M. Frank. 1986. Inherited deficiencies of complement and complement-related proteins. Clin. Immunol. Immunopathol. 40:37-49.

4. Alper, C. A., N. Abramson, R. B. Johnston, J. H. Jandl, and F. S. Rosen. 1970. Increased susceptibility to infection associated with abnormalities of complement-mediated functions and of the third component of complement (C3). N. Engl. J. Med. 282:349-354.

5. Thompson, R. A., and P. J. Lachmann. 1977. A second case of human C3b inhibitor (KAF) deficiency. Clin. Exp. Immunol. 27:2329.

6. Eng, R. H. K., S. J. Seligman, M. A. Arnaout, and C. A. Alper. 1978. Variable expression of homozygous $\mathrm{C} 3 \mathrm{~b}$ inactivator deficiency. Clin. Res. 26:394a. (Abstr.)

7. Wahn, V., U. Rother, E. W. Rauterberg, N. K. Day, and A. B. Laurell. 1981. C3b Inactivator deficiency: association with an alphamigrating factor H. J. Clin. Immunol. 1:228-233.

8. Solal-Celigny, P., M. Laviolette, J. Herbert, P. C. Atkins, M. Sirois, G. Brun, G. Lehner-Netsch, and J. M. Delâge. 1982. C3b inactivator deficiency with immune complex manifestations. Clin. Exp. Immunol. 47:197-205.

9. Thompson, R. A., and M. H. Winterborn. 1981. Hypocomplementaemia due to a genetic deficiency of $\beta 1 \mathrm{H}$ globulin. Clin. Exp. Immunol. 46:110-119.

10. Sjöholm A. G., J. H. Braconier, and C. Söderström. 1982. Properdin deficiency in a family with fulminant meningococcal infections. Clin. Exp. Immunol. 50:291-297. 
11. Kluin-Nelemans, H. C., H. van Velzen-Blad, H. P. T. van Helden, and M. R. Daha. 1984. Functional deficiency of complement factor D in a monozygous twin. Clin. Exp. Immunol. 58:724-730.

12. Reid, K. B. M., D. M. A. Johnson, J. Gagnon, and R. Prohaska. 1981. Preparation of human factor D of the alternative pathway of complement. Methods Enzymol. 80:134-143.

13. Laemmli, U. K. 1970. Cleavage of structural proteins during the assembly of the head of bacteriophage T4. Nature (Lond.). 227:680-685.

14. Salvatore, G., M. Salvatore, H. J. Cahnmann, and J. Robbins. 1964. Separation of thyroidal iodoproteins and purification of thyroglobulin by gel filtration and density gradient centrifugation. J. Biol. Chem. 239:3267-3274.

15. Mayer, M. M. 1961. Complement versus complement fixation. In Experimental Immunochemistry. E. A. Kabat and M. M. Mayer, editors. Charles C. Thomas, Springfield, IL. 133-240.

16. Daha, M. R., and L. A. van Es. 1981. Enhanced alternative complement pathway-dependent degradation of soluble immunoglobulin aggregates by macrophages. Immunology. 43:513-518.

17. Leijh, P. C. J., M. Th. van den Barselaar, T. L. van Zwet, M. R. Daha, and R. van Furth. 1979. Requirement of extracellular complement and immunoglobulin for intracellular killing of micro-organisms by human monocytes. J. Clin. Invest. 63:772-784.

18. Daha, M. R., R. M. Bertina, J. Thompson, R. H. Kauffmann, A. Nicholson-Weller, J. J. Veltkamp, and E. Briet. 1982. Combined hereditary deficiency of the sixth component of complement and factor VIII coagulant activity in a Dutch family. Clin. Exp. Immunol. 48:733-738.

19. Johnson, U., L. Truedsson, and B. Gustavii. 1983. Complement components in 100 newborns and their mothers determined by electroimmunoassay. Acta Pathol. Microbiol. Immunol. Scand. C. 91:147-150.
20. Leijh, P. C. J., R. van Furth, and T. L. van Zwet 1986. In vitro determination of phagocytosis and intracellular killing by polymorphonuclear and mononuclear phagocytes. In Handbook of Experimental Immunology. Vol. 2. Cellular Immunology. D. M. Weir, editor. Blackwell Scientific, Oxford. 46.1-46.21.

21. Fearon, D. T., K. F. Austen, and S. Ruddy. 1974. Properdin factor D. Characterization of its active site and isolation of the precursor form. J. Exp. Med. 139:355-366.

22. Lesavre, P. H., and H. J. Müller-Eberhard. 1978. Mechanism of action of factor D of the alternative complement pathway. J. Exp. Med. 148:1498-1509.

23. Niemann, M. A., A. S. Bhown, J. C. Bennett, and J. E. Volanakis. 1984. Amino acid sequence of human $D$ of the alternative pathway. Biochemistry. 23:2482-2486.

24. Mole, J. E., and J. K. Anderson. 1987. Cloning the cDNA for complement factor $\mathrm{D}$ : evidence for the existence of a zymogen for the serum enzyme. Complement. 4:196. (Abstr.)

25. Truedsson, L., and G. Sturfelt. 1983. Human factor D of the alternative pathway: purification and quantitation by enzyme amplified electroimmunoassay. J. Immunol. Methods. 63:207-214.

26. Barnum, S. R., M. A. Niemann, J. F. Kearny, and J. E. Volanakis. 1984. Quantitation of complement factor $D$ in human serum by a solid-phase radioimmunoassay. J. Immunol. Methods. 67:303-309.

27. Volanakis, J. E., S. R. Barnum, M. Giddens, and J. H. Galla. 1985. Renal filtration and catabolism of complement protein D. $N$. Engl. J. Med. 312:395-399.

28. Sjöholm, A. G., E. J. Kuijper, C. C. Tijssen, A. Jansz, P. Bol, L. Spanjaard, and H. C. Zanen. 1988. Dysfunctional properdin in a Dutch family with meningococcal disease. N. Engl. J. Med. 319:33-37.

29. Petersen, B. H., T. J. Lee, R. Snyderman, and G. F. Brooks. 1979. Neisseria meningitidis and Neisseria gonorrhoea bacteremia associated with C6, C7, or C8 deficiency. Ann. Intern. Med. 90:917-920. 